\title{
TIM-4 is expressed on invariant NKT cells but dispensable for their development and function
}

\author{
Xilin Zhang ${ }^{1,2,3}$, Jun Gu${ }^{3}$, Li Zhou ${ }^{1,2,4,5}$ and Qing-Sheng Mi ${ }^{1,2,4,5}$ \\ ${ }^{1}$ Henry Ford Immunology Program, Henry Ford Health System, Detroit, MI, United States of America \\ 2 Department of Dermatology, Henry Ford Health System, Detroit, MI, United States of America \\ 3 Department of Dermatology, Changhai Hospital, Second Military Medical University, Shanghai, China \\ ${ }^{4}$ Department of Internal Medicine, Henry Ford Health System, Detroit, MI, United States of America \\ ${ }^{5}$ Department of Immunology and Microbiology, Wayne State University School of Medicine, MI, United States of America \\ Correspondence to: Qing-Sheng Mi, email: qmil@hfhs.org \\ Li Zhou, email: Izhoul@hfhs.org
}

Keywords: TIM-4, invariant NKT cells, development, function, polarization, Immunology and Microbiology Section, Immune response, Immunity

Received: August 08, 2016

Accepted: September 12, 2016

Published: September 20, 2016

ABSTRACT

T cell immunoglobulin and mucin-4 (TIM-4), mainly expressed on antigen presenting cells, plays a versatile role in immunoregulation. CD1d-restricted invariant natural killer $T$ (iNKT) cells are potent cells involved in the diverse immune responses. It was recently reported that recombinant TIM-4 (rTIM-4) alone enhanced cytokine production in NKT hybridoma, DN32.D3 cells. Hence, we hypothesized that TIM4 might regulate iNKT cell biology, especially their function of cytokine secretion. For the first time, we identified that TIM-4 was expressed in thymus iNKT cells, and its expression increased upon iNKT cell migration to the secondary lymphoid organs, especially in lymph nodes. Using TIM-4-deficient mice, we found that lack of TIM-4 did not disturb iNKT cell development, maturation, peripheral homeostasis and cytokine secretion. Moreover, TIM-4 deficiency did not alter the polarization of iNKT sublineages, including NKT1, NKT2 and NKT17. Finally, the mixed bone marrow transfer experiments further confirmed normal iNKT cell development and function from TIM-4-deficient bone marrow. In conclusion, our data suggest that TIM-4 is expressed on iNKT cells but dispensable for their development and function.

\section{INTRODUCTION}

Natural killer T (NKT) cells comprise a unique subset of $\alpha \beta \mathrm{T}$ cells that coexpress a semi-invariant T-cell receptor (TCR) and natural killer (NK) cell-related surface markers. They stringently respond to glycolipid antigens, such as $\alpha$-galactosylceramide ( $\alpha$-GalCer), presented by the major histocompatibility complex (MHC) class I-like molecule CD1d [1]. Two major types of NKT cells have been described in mice: type I invariant NKT (iNKT) cells are the most abundant subset which express Va14J $\alpha 18$ TCR- $\alpha$ rearrangement together with V $\beta 8.2$, V $\beta 7$, or V $\beta 2$ TCR- $\beta$ chains, whereas type II NKT cells display heterogeneous TCR $\alpha \beta$ chain combinations [2]. Within hours of activation, iNKT cells simultaneously produce large amounts of cytokines, including interferon (IFN)- $\gamma$, interleukin (IL)-4 and IL-17, which greatly contribute to diverse immune responses, including antimicrobial immunity, tumor rejection, allergy and autoimmune diseases [3-5]. Therefore, it is essential to understand the mechanisms governing iNKT cell development and function.

iNKT cells derive from $\mathrm{CD} 4^{+} \mathrm{CD} 8^{+}$double-positive (DP) thymus precursors and undergo four distinct stages of differentiation involving sequential downregulation of CD24 and upregulation of CD44 and NK1.1 [6-9]. Firstly, the DP thymocytes, expressing V $\alpha 14-J \alpha 18$ TCR- $\alpha$ chain as well as signaling lymphocytic-activation molecule (SLAM) co-receptor, are positively selected to become stage 0 iNKT cells (CD24+ CD44 $\left.4^{\text {low }} \mathrm{NK} 1.1^{-}\right)$. Next, stage 0 iNKT cells lower their CD24 expression and turn into highly-proliferative stage 1 (CD24 $4^{\text {low }}$ CD $44^{\text {low }}$ NK1.1 
) and, subsequently, stage $2\left(\mathrm{CD} 24^{\text {low }} \mathrm{CD} 44^{\text {high }} \mathrm{NK} 1.1^{-}\right)$ iNKT cells. Finally, most of stage 2 iNKT cells leave the thymus, complete maturation and become stage 3 iNKT cells $\left(\mathrm{CD} 24^{\text {low }} \mathrm{CD} 44^{\text {high }} \mathrm{NK} 1.1^{+}\right)$in the peripheral organs, while a minority reside and mature inside the thymus [10]. Recent evidence further modified this notion of sequential developmental process in iNKT cells [11, 12]. Resembling $\mathrm{T}$ helper (Th) cells, iNKT cells are at least classified into three polarized sublineages, including NKT1, NKT2 and NKT17, based on their expression of transcription factors T-bet, GATA-3, and ROR $\gamma \mathrm{t}$ with the distinct secretion of IFN- $\gamma$, IL-4 and IL-17, respectively. Despite great advances in understanding the biology of iNKT cells, the detailed underlying mechanisms remain elusive.

The T-cell immunoglobulin domain and mucin domain (TIM) family of genes was first cloned in the $\mathrm{T}$ cell and airway phenotype regulator (Tapr) locus as a novel allergy susceptibility gene [13]. It consists of eight members (encoding TIM-1 to TIM-4 and putative TIM5 to TIM-8) in mice, which are located on chromosome 11B1.1, while three members Tim-1, Tim-3 and Tim-4 in humans are located on chromosome 5q33.2 [14]. All the TIM members share an analogous structure of cellsurface Type 1 membrane protein, containing a N-terminal Cysteine-rich immunoglobulin (Ig) variable-like domain, a mucin-like glycosylated domain, a transmembrane domain and an intracellular tail [15]. Previous studies underscored an essential role of TIM family in diverse immune responses, involving viral infection, allergy, autoimmunity, transplant tolerance and tumor immunity [16-18]. The underpinning mechanisms were principally attributed to their regulation of $\mathrm{T}$ cell polarization. Highaffinity TIM-1-specific agonist antibody promoted Th1 and Th17 responses, but inhibited regulatory T cell (Treg) differentiation; low-affinity TIM-1 engagement enhanced Th2 polarization with compromised $\mathrm{T}$ cell proliferation [19]. And, TIM-2 preferentially promoted Th2 response, while TIM-3 specifically inhibited Th1 differentiation [20, 21].

TIM-4, also named as SMUCKLER (spleen, mucincontaining, knockout of lymphotoxin), was originally identified by gene expression profiling in 2004 [22]. Being the sole TIM member absent in conventional T cells, TIM-4 was mainly expressed in "professional" antigen-presenting cells (APC) under physiological status, including macrophages and dendritic cells (DC) [23-25]. Also, unlike other TIM members, TIM-4 lacks tyrosine phosphorylation motifs on the intracellular tail, which forbids mediating direct signaling of its own [26]. Nevertheless, previous studies demonstrated a pleiotropic immunoregulatory role of TIM-4, functioning as either a costimulatory molecule or as a phosphatidylserine (PS) receptor for apoptotic bodies. As a natural ligand for TIM-1, TIM-4 provoked pre-activated T cell expansion; however, TIM-4 suppressed naïve T cell proliferation by binding to an unknown ligand excluding TIM-1 [23, 27].
Furthermore, TIM- 4 regulated the polarization of $\mathrm{CD}^{+}$ naïve $\mathrm{T}$ cells towards Th2, Th17 and regulatory $\mathrm{T}$ (Treg) sublineages [28-30].

Recently, Kim et al discovered that unlike conventional $\mathrm{T}$ cells, mouse hepatic iNKT cells and DN32.D3 NKT hybridoma cells constitutively expressed TIM-4 and TIM-1 at a substantial level [31]. Intriguingly, recombinant TIM-4 (rTIM-4) alone, but not recombinant TIM-1 (rTIM-1), enhanced the cytokine production of DN32.D3 NKT hybridoma cells. Moreover, silencing of TIM-4 profoundly lowered IFN- $\gamma$ and IL-4 secretion by TIM-1-engaged DN32.D3 cells in vitro. Hence, we hypothesized that TIM-4 might control iNKT cell biology, especially its function. In this study, for the first time, we uncovered the expression pattern of TIM-4 in iNKT cells located in various lymphoid organs. Using global TIM-4 knockout $(\mathrm{KO})$ mice with a mixed bone marrow transfer model, we demonstrated that TIM-4 was not required for iNKT cell homeostasis, development, maturation and cytokine secretion as well as the polarization of their sublineages.

\section{RESULTS}

\section{TIM-4 is differentially expressed in iNKT cells from different lymphoid organs}

Consistent with a previous report [24], TIM-4 deficiency did not affect the cellularities of different lymphoid organs (Figure S1). To detect TIM-4 expression in the immature and mature iNKT cells in different lymphoid organs, lymphocytes from thymus, spleen, skindraining lymph nodes (LN) and liver of TIM-4 KO and wild-type (WT) mice were stained with antibodies against TCR- $\beta$, PBS57-CD1d tetramer, NK1.1 and TIM-4. As shown in Figure 1a, thymus iNKT cells barely expressed TIM-4, while the iNKT cells residing at the secondary lymphoid organs exhibited a considerable increase of TIM-4 expression. Among them, LN iNKT cells expressed TIM-4 at the highest level. Compared with their immature counterparts, mature NK1.1 ${ }^{+}$iNKT cells in the thymus, spleen and LNs expressed higher levels of TIM-4, although there was no significant difference between the NK1.1 ${ }^{-}$and NK1.1 $1^{+}$subsets of LN iNKT cells (Figure 1b). In a nutshell, TIM-4 is differentially expressed by iNKT cells, based on their location and maturation status.

\section{TIM-4 is not required for iNKT cell development}

To assess the role of TIM-4 in iNKT cell development, we compared the percentage and absolute number of iNKT cells from TIM-4 WT and KO mice. As shown in Figure 2, lack of TIM-4 did not alter iNKT cell ratio or cell count within any lymphoid organ. Equivalent 

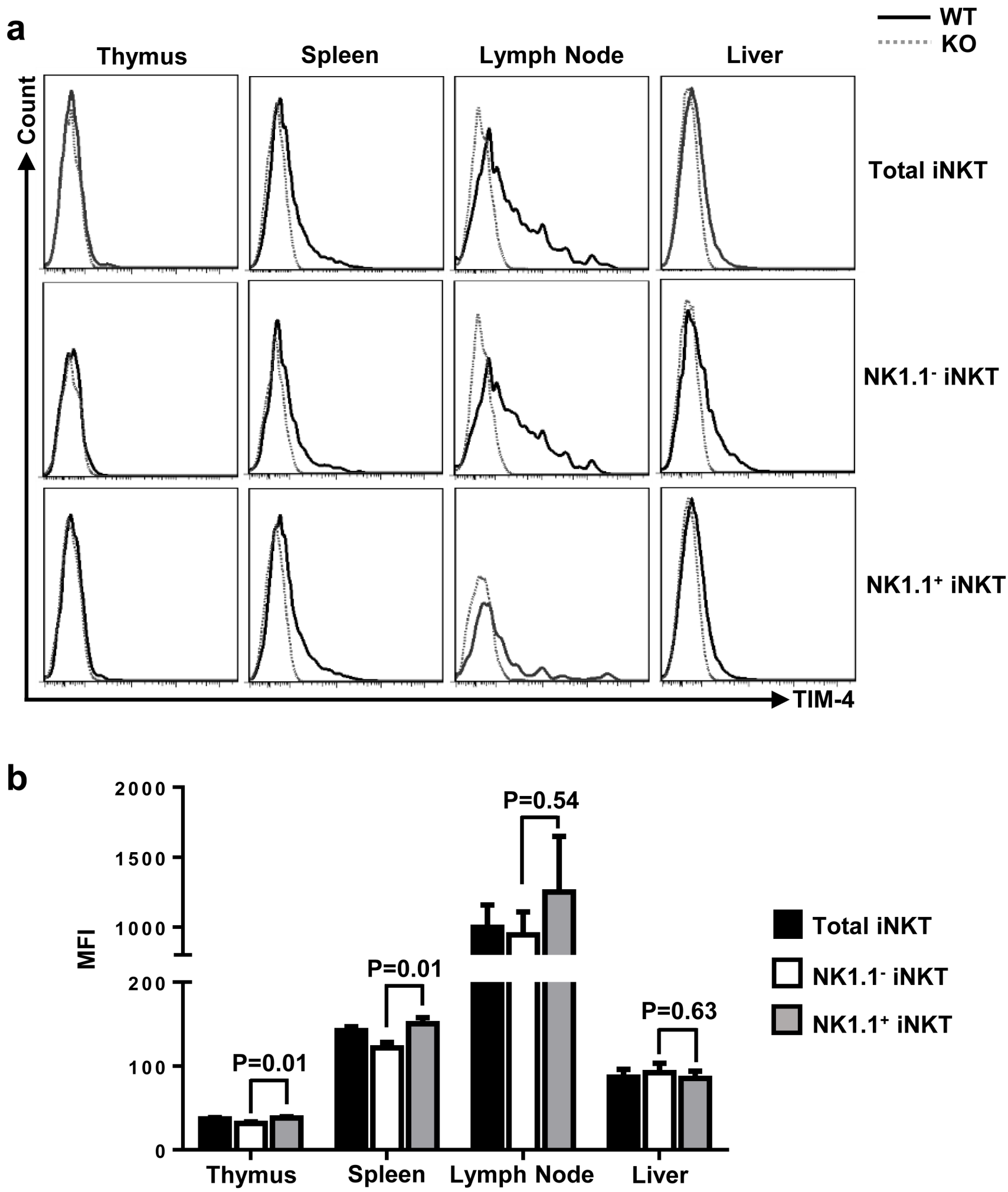

Figure 1: TIM-4 expressions in iNKT cells. a. The histograms of TIM-4 expressions in the iNKT cells of different lymphoid organs with further evaluation of NK1.1 ${ }^{-}$and NK1.1 ${ }^{+}$iNKT subsets. Solid black histogram represents TIM-4 expression in the iNKT cells from TIM-4 WT mice; and dashed grey histogram represents TIM-4 expression in the iNKT cells from TIM-4 KO mice. Data represent one of three independent experiments, with 4 mice per experiment. b. The mean fluorescence intensity (MFI) of TIM-4 expression in the total iNKT cells, NK1.1 $1^{-}$and NK1.1 ${ }^{+}$iNKT cell subpopulations of different lymphoid organs from TIM-4 WT mice. Black bar represents total iNKT cells; white bar represents NK1.1- iNKT cells; and grey bar represents NK1.1 ${ }^{+}$iNKT cells. The bar graph (mean \pm SEM) represents three independent experiments, with 1-2 mice per experiment. 
proliferative and apoptotic rates of iNKT cells from TIM$4 \mathrm{WT}$ and KO mice were also found, which ruled out the possibility that TIM-4 might have an impact on iNKT cell turnover (Figure S2). Therefore, TIM-4 appears to be dispensable for iNKT cell development.

TIM-4 deficiency does not alter iNKT cell maturation

As the expression of TIM-4 in iNKT cells enhanced upon maturation, we explored the possibility that TIM-4 might modulate the maturation process of iNKT cells. As depicted in Figure $3 \mathrm{a}$ and $3 \mathrm{~b}$, the frequencies of stage 0 to stage 3 iNKT cells within the thymus were all comparable between TIM-4 WT and KO mice. Further analysis of the secondary lymphoid organs showed that the percentage of mature iNKT cells, which expressed NK1.1, remained equivalent between TIM-4 WT and KO mice (Figure $3 \mathrm{c}$ ). In addition to NK1.1, the maturation of iNKT cells are also accompanied by the upregulated expressions of several other cell surface receptors, such as CD122 and CD69. In accordance with the aforementioned results, TIM-4 deficiency did not alter the frequencies of CD122and CD69-positive iNKT cells (Figure 3d, 3e). Together, our data suggest that TIM-4 is not required for iNKT cell maturation.

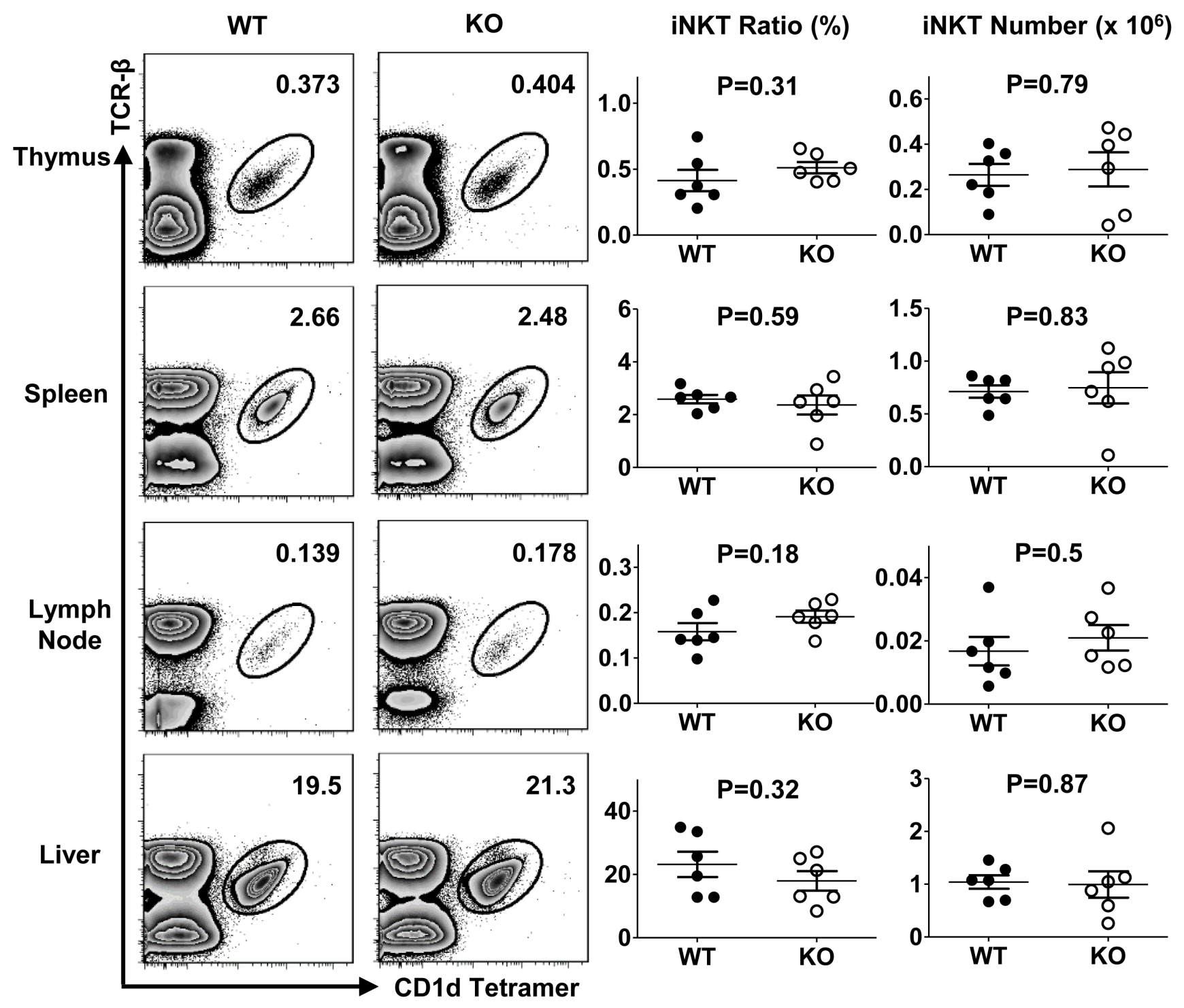

Figure 2: TIM-4 is not required for iNKT cell development. Representative dot plots of thymus, spleen, lymph node and liver iNKT cells stained with anti-TCR- $\beta$ antibody and CD1d tetramer from TIM-4 WT and KO mice (left panel). The frequency (middle panel) and number (right panel) of TCR- $\beta^{+} \mathrm{CD} 1 \mathrm{~d}$-tetramer ${ }^{+}$iNKT cells within different lymphoid organs. Each point represents one individual mouse, and the mean values are indicated by middle horizontal lines from three independent experiments with 4 mice per experiment. 
a
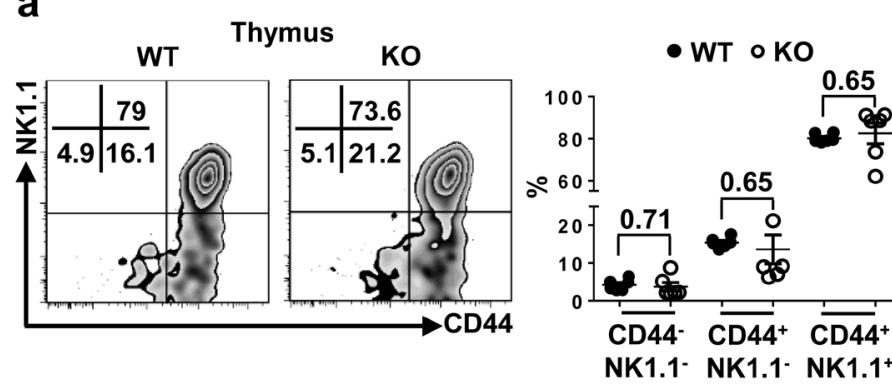

d

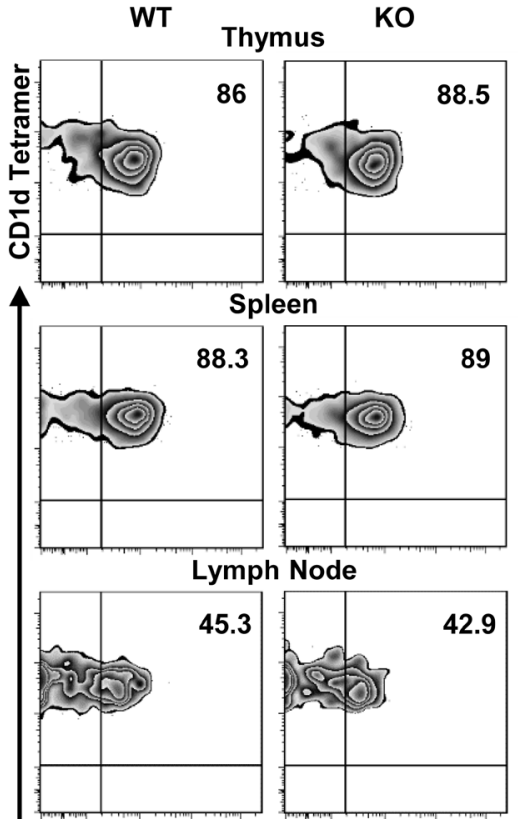

CD122+ iNKT (\%)

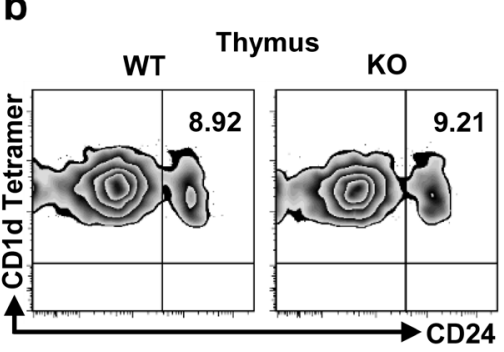

$\mathrm{CD}^{+}{ }^{+}$iNKT (\%)

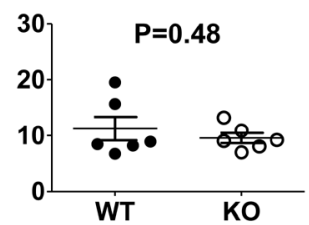

C

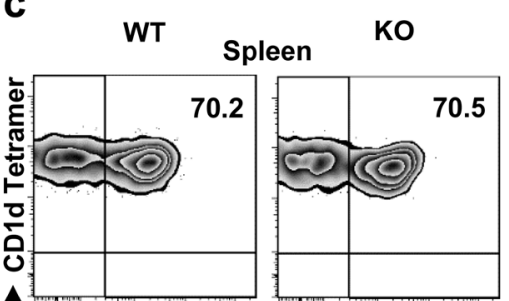

NK1.1 + iNKT (\%)
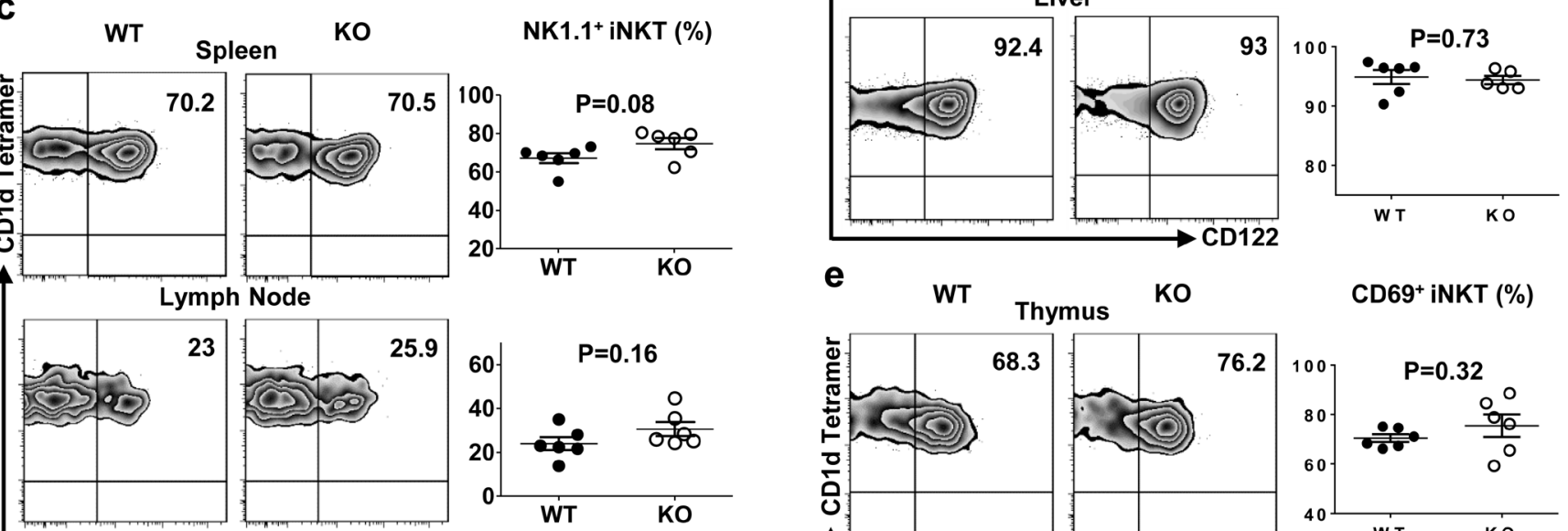

e
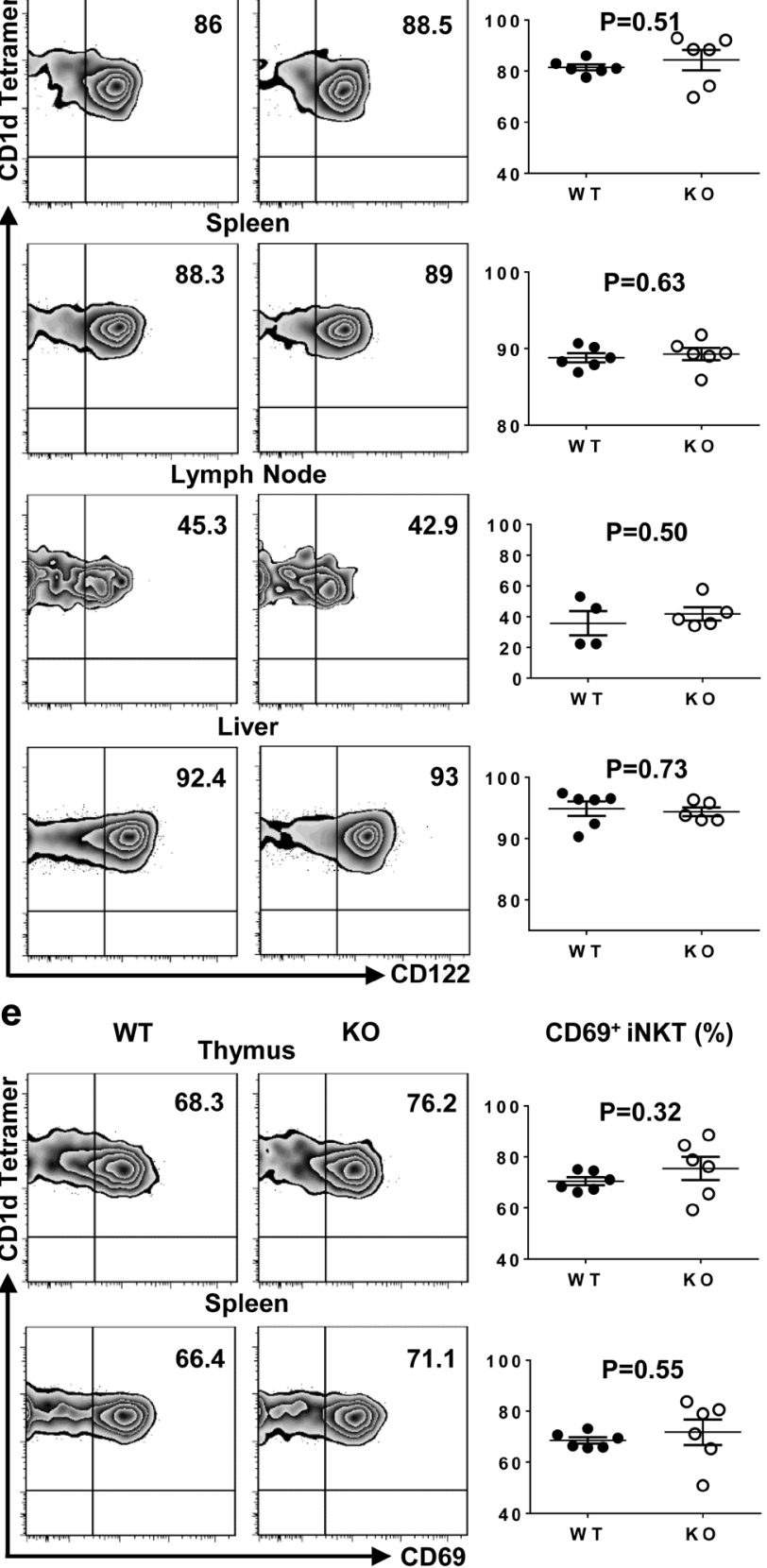

CD69+ iNKT (\%)
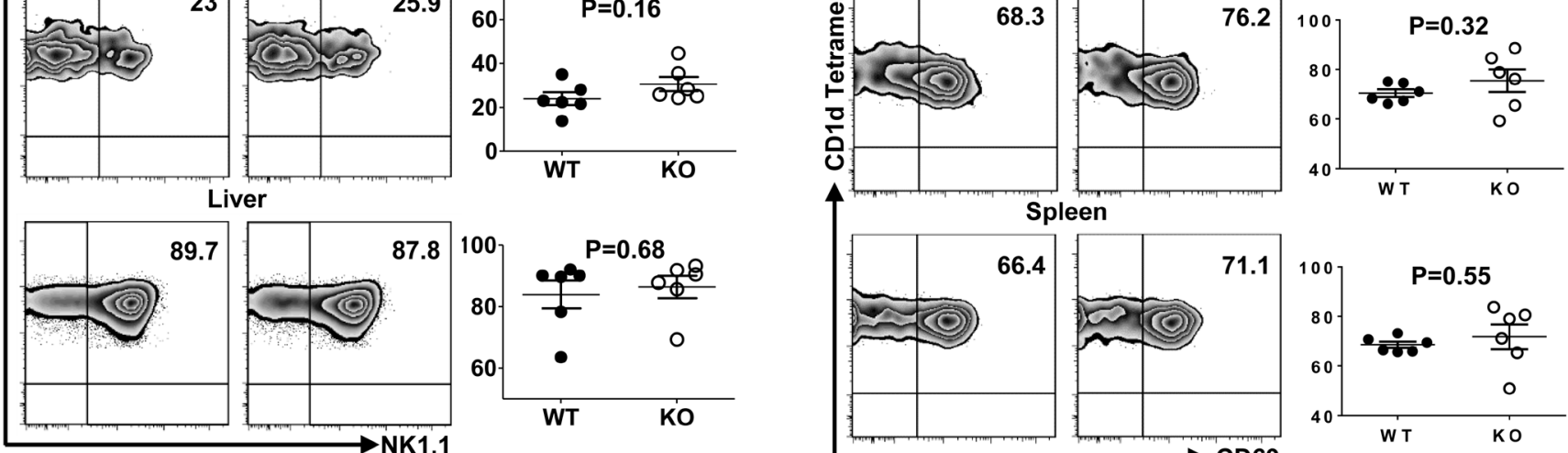

Figure 3: TIM-4 deficiency does not alter iNKT cell maturation. a. Representative dot plots depict CD44 and NK1.1 expression in thymus iNKT cells of TIM-4 WT and KO mice (left panel). The percentages of iNKT cell subpopulations based on their CD44 and NK1.1 expression patterns gated on thymus TCR- $\beta^{+}$CD1d-tetramer ${ }^{+}$iNKT cells (right panel). Black dot represents the percentage of thymus iNKT cell subset from TIM-4 WT mice, and white dot represents the percentage of thymus iNKT cell subset from TIM-4 KO mice. Each point represents one individual mouse, and the mean values are indicated by middle horizontal lines from three independent experiments with 4 mice per experiment. b. Flow cytometry analysis (left panel) and percentage (right panel) of CD24-positive thymus iNKT cells from TIM-4 WT and KO mice. Data represent three independent experiments with 4 mice per experiment. c. Flow cytometry analysis (left panel) and percentage (right panel) of NK1.1-positive iNKT cells in the spleen, lymph node and liver of TIM-4 WT and KO mice. Data represent three independent experiments with 4 mice per experiment. d. Flow cytometry analysis (left panel) and percentage (right panel) of CD122-positive iNKT cells in the thymus, spleen, lymph node and liver of TIM-4 WT and KO mice. Data represent at least two independent experiments with 4-5 mice per experiment. e. Flow cytometry analysis (left panel) and percentage (right panel) of CD69positive iNKT cells in the thymus and spleen of TIM-4 WT and KO mice. Data represent three independent experiments with 4 mice per experiment. 


\section{Normal iNKT cell function in TIM-4 KO mice}

The prompt secretion of a large amount of cytokines upon activation is crucial to the immunoregulatory function of iNKT cells. To explore the role of TIM4 in iNKT cell function, spleen and skin-draining LN cells were stimulated in vitro with phorbol 12-myristate 13-acetate (PMA) and ionomycin for 3 hours, which bypassed proximal TCR-mediated signaling events. The secretion of IFN- $\gamma$, IL-4 and IL-17 as well as CD69 expression in both spleen and LN iNKT cells were comparable between TIM-4 WT and KO mice (Figure 4a, $4 c)$. Next, we injected mice with $\alpha$-GalCer to specifically stimulate iNKT cells in vivo. Consistently, 2 hours after $\alpha$-GalCer treatment, loss of TIM- 4 did not affect the cytokine secretions and CD69 expression by spleen iNKT cells (Figure 4b). Hence, TIM-4 deficiency does not alter iNKT cell function.

\section{Lack of TIM-4 does not affect the polarization of iNKT cell sublineages}

To investigate whether TIM-4 regulated the polarization of iNKT cell sublineages, we examined the expressions of transcription factors in thymus and spleen iNKT cells. As shown in Figure 5a and 5b, both the frequency and mean fluorescence intensity (MFI) of T-bet, GATA-3 and ROR $\gamma$ t were equivalent between TIM-4 WT and $\mathrm{KO}$ mice. Along with their intact cytokine-secreting function, the proper expression of transcription factors in TIM-4-deficient iNKT cells further confirm that TIM-4 deficiency does not disturb the polarization of iNKT cell subsets.

\section{Normal iNKT cell development and function in a mixed bone marrow transfer model}

The differentiation of iNKT cells and their function are shaped conjointly by both progenitor cells from the bone marrow (BM) and local microenvironment. To further determine whether the normal development and function of TIM-4-deficient iNKT cells are compensated by TIM-4-deficient environmental factors, we utilized a mixed bone marrow transfer model, in which iNKT cell precursors from both TIM-4 WT and KO mice were positioned within the same normal microenvironment. As depicted in Figure 6a, the BM from TIM-4 KO mice reconstituted iNKT cells comparably to that of WT mice. When analyzing NK1.1/CD44 profile in the thymus, equivalent frequencies of developmental iNKT cells were detected between TIM-4 KO and WT BM origins (Figure 6b). Similar results were obtained when assessing the percentages of NK1.1-, CD122- and CD69-positive spleen iNKT cells (Figure 6c). After in vitro stimulation with PMA and ionomycin for 3 hours, the production of IFN- $\gamma$, IL-4 and IL-17 along with CD69 expression were comparable between TIM-4 WT and KO BM-derived spleen iNKT cells (Figure 6d). Consistently, the expression of T-bet, GATA-3 and ROR $\gamma$ t in spleen iNKT cells were also equivalent (Figure 6e). Overall, our BM transferring data further support the notion that TIM-4 is not required for iNKT cell development and function.

\section{DISCUSSION}

TIM-4 was originally identified to be preferentially expressed in peripheral lymphoid tissues, including splenic white pulp and marginal zone, LN subcapsular sinus and paracortex area as well as Peyer's patches [22]. Later on, TIM-4 expression was predominantly detected in typical APCs, including macrophages and dendritic cells, other than conventional T cells [23-25]. To the best of our knowledge, we are the first to report that TIM4 is differentially expressed in iNKT cells residing at various lymphoid organs, and its expression is generally upregulated in mature iNKT cells.

TIM-4 plays a pleiotropic role in T cell immunity by specific ligations to other molecules expressed on conventional T cells. TIM-4 was initially recognized to be a natural ligand of TIM-1, and in vivo administration of TIM-4-Ig fusion protein stimulated TIM-1-expressing preactivated T cell proliferation [23]. However, Mizui et al [27] showed that TIM-4-Ig fusion protein could also bind to other unknown receptors and exert an inhibitory activity on naïve $\mathrm{T}$ cells, which did not express TIM-1. In addition, TIM-4 is capable of modulating Th cell differentiation. TIM-4 generally favors a Th2 over Th1 polarization after environmental disturbance [24, 28, 32, 33]. TIM-4-Ig fusion protein suppressed the in vitro differentiation of $\mathrm{CD}^{+} \mathrm{T}$ cells into the Th17 phenotype [29]. Recently, Yeung et al [30] demonstrated that in vivo blockade of TIM-4 by antibodies promoted skin allograft survival by conversion of naïve $\mathrm{CD}^{+} \mathrm{T}$ cells to allospecific induced Tregs. Altogether, TIM-4 displays a versatile role in regulating T cell immunity even though it is not expressed by conventional $\mathrm{T}$ cells.

Previous studies suggest that TIM molecules profoundly impact the biology of iNKT cells. In the presence of TCR stimulation, TIM-1 costimulation on DN32.D3 NKT hybridoma cells enhanced the cellular secretion of IL-4 while preventing the production of IFN- $\gamma$ [31]. TIM-1 also mediated the binding of hepatitis A virus (HAV) by human liver NKT cells as well as the activation of human NKT cells triggered by HAV [34]. In addition, TIM-1 facilitated pulmonary iNKT cells to bind rather than engulf apoptotic cells as a typical PS receptor, which enhanced iNKT cell production of IFN- $\gamma$ and IL-4 and subsequent initiation of airway hyperreactivity [35]. On the other hand, ligation of TIM-3 by galectin-9 in hepatic TIM- $3^{+}$NKT cells led to activation-induced apoptosis and 
a

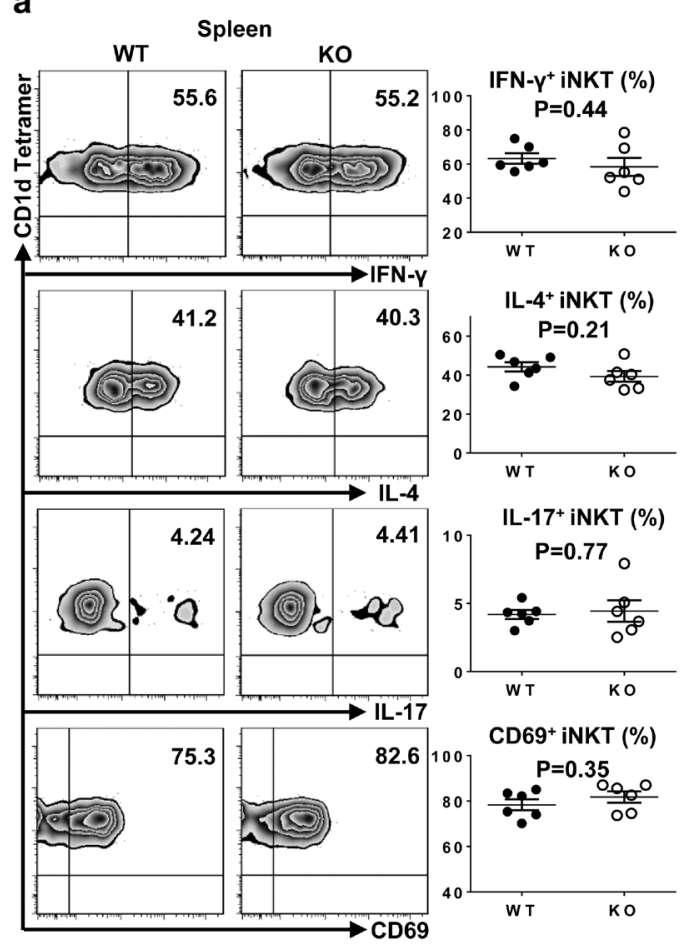

C

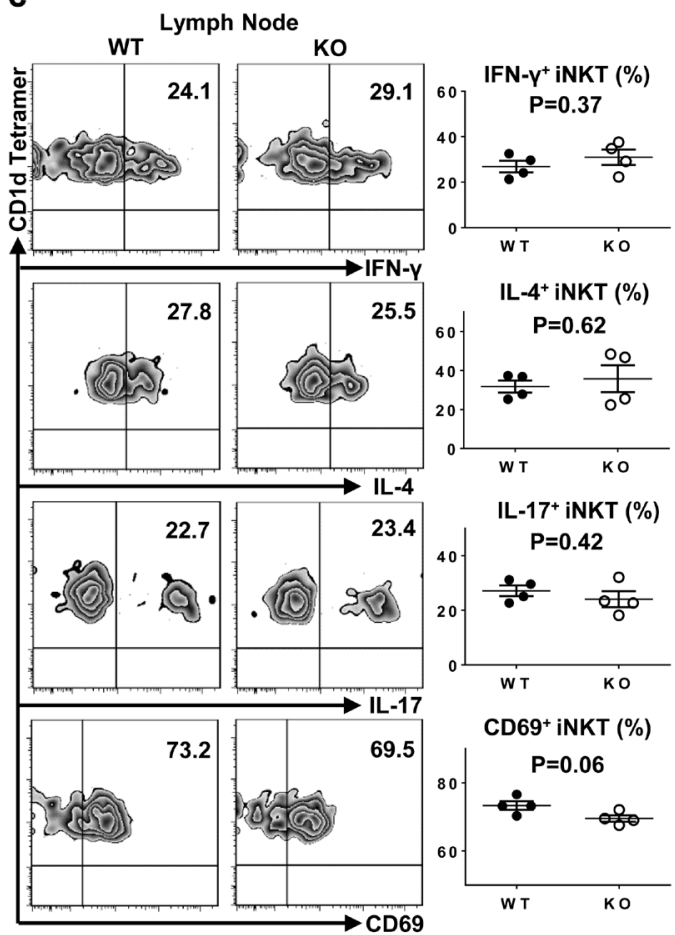

b

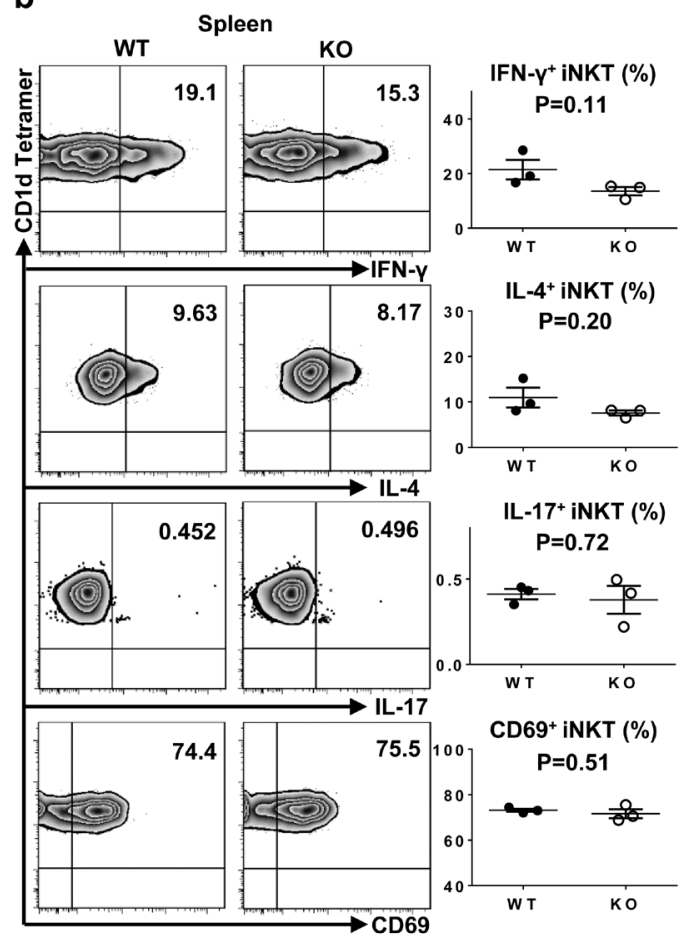

Figure 4: Normal iNKT cell function in TIM-4 KO mice. a. Representative dot plots of IFN- $\gamma$, IL-4, IL-17 and CD69 expressions in spleen iNKT cells of TIM-4 WT and KO mice after PMA and ionomycin treatment in vitro for 3 hours (left panel). The percentages of IFN- $\gamma$-, IL-4-, IL-17- and CD69-positive iNKT cells (right panel). Each point represents one individual mouse, and the mean values are indicated by middle horizontal lines from three independent experiments with 4 mice per experiment. b. Representative dot plots of IFN- $\gamma$, IL-4, IL-17 and CD69 expressions in spleen iNKT cells of TIM-4 WT and KO mice after in vivo $\alpha$-Galcer stimulation for 2 hours (left panel). The percentages of IFN- $\gamma$-, IL-4-, IL-17- and CD69-positive iNKT cells (right panel). Data represent six mice. c. Representative dot plots of IFN- $\gamma$, IL-4, IL-17 and CD69 expressions in the lymph node iNKT cells from TIM-4 WT and KO mice after PMA and ionomycin treatment in vitro for 3 hours (left panel). The percentages of IFN- $\gamma$-, IL-4-, IL-17- and CD69-positive iNKT cells (right panel). Data represent two independent experiments with 4 mice per experiment. 

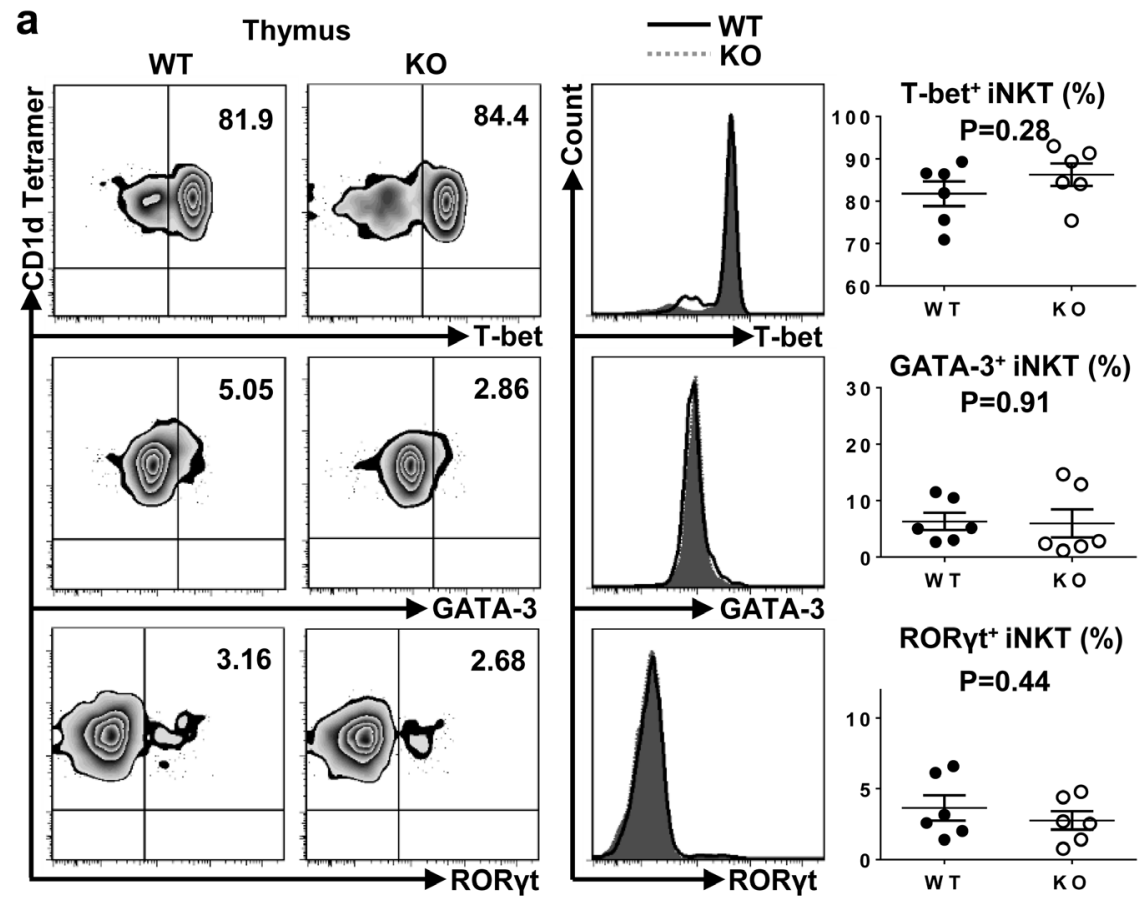

RORYt ${ }^{+}$iNKT (\%)

$$
P=0.44
$$

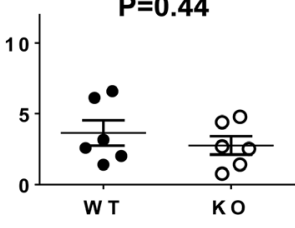

b
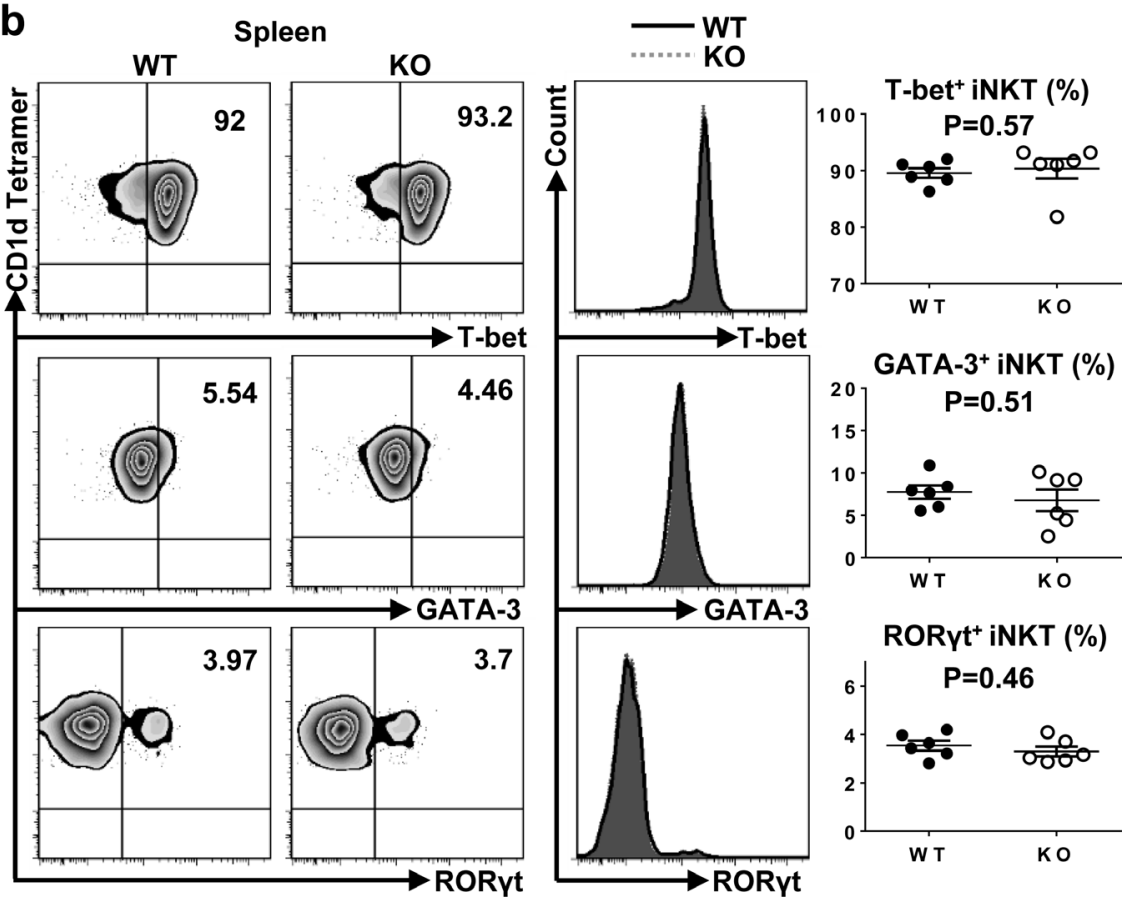

RORYt ${ }^{+}$iNKT (\%)

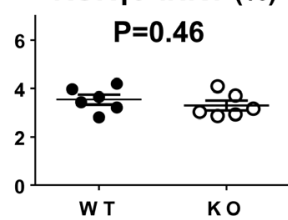

Figure 5: Loss of TIM-4 does not affect the polarization of iNKT cell sublineages. a. Representative dot plots of T-bet, GATA3 and ROR $\gamma t$ expressions in the thymus iNKT cells from TIM-4 WT and KO mice (left panel). The histograms of T-bet, GATA-3, and ROR $\gamma t$ expressions in the thymus iNKT cells (middle panel). Solid black histogram represents the expression of transcription factor in the iNKT cells from TIM-4 WT mice; shaded grey histogram represents the expression of transcription factor in the iNKT cells from TIM-4 KO mice. The percentages of T-bet-, GATA-3- and ROR $\gamma$ t-positive thymus iNKT cells (right panel). Each point represents one individual mouse, and the mean values are indicated by middle horizontal lines from three independent experiments with 4 mice per experiment. $\mathbf{b}$. Representative dot plots of T-bet, GATA-3 and ROR $\gamma \mathrm{t}$ expressions in the spleen iNKT cells from TIM-4 WT and KO mice (left panel). The histograms of T-bet, GATA-3, and ROR $\gamma t$ expressions in the spleen iNKT cells (middle panel). Solid black histogram represents the expression of transcription factor in the iNKT cells from TIM-4 WT mice; and shaded grey histogram represents the expression of transcription factor in the iNKT cells from TIM-4 KO mice. The percentages of T-bet-, GATA-3-, and ROR $\gamma$ t-positive spleen iNKT cells (right panel). Data represent three independent experiments with 4 mice per experiment. 

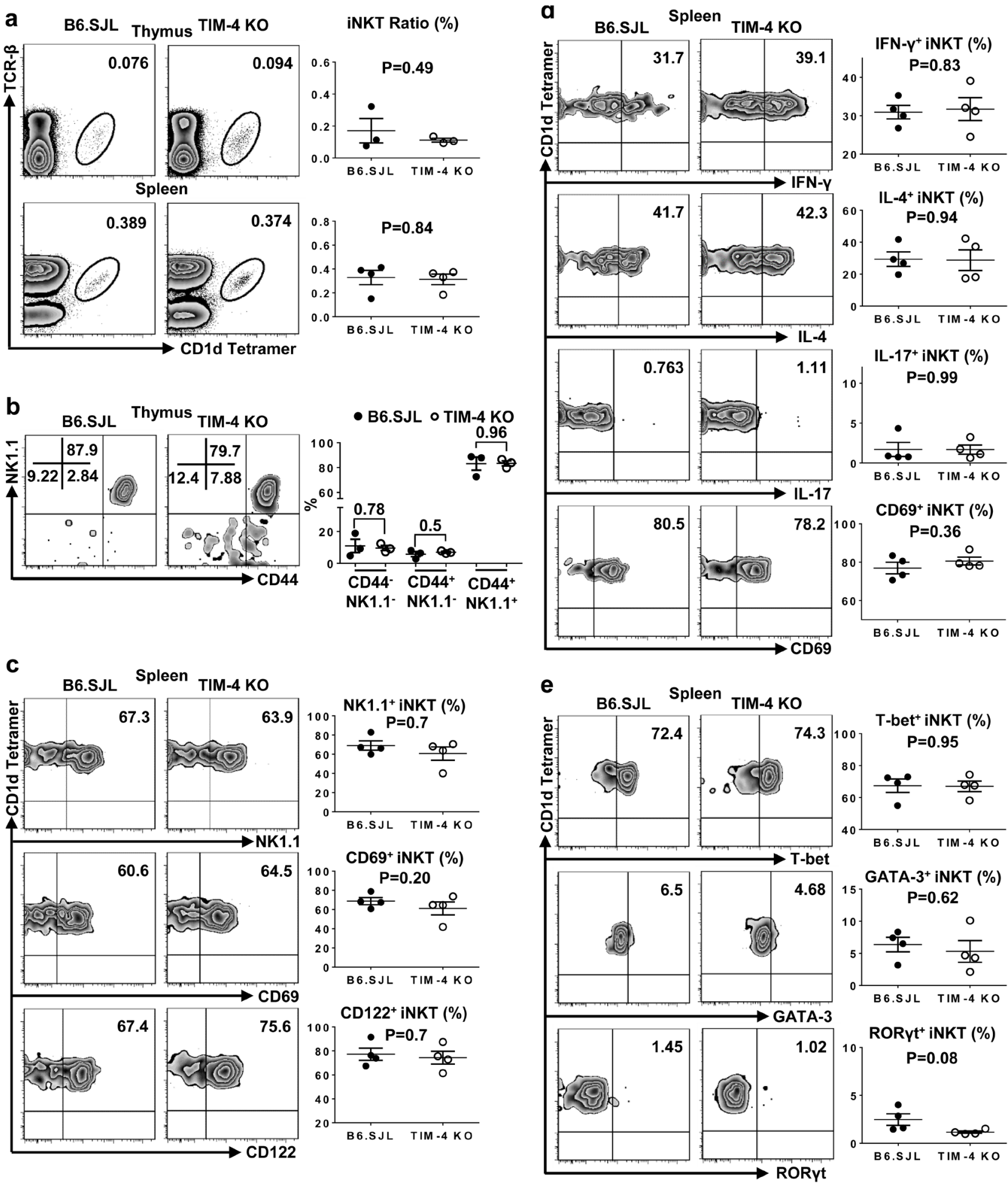

Figure 6: Normal iNKT cell development and function are cell-intrinsic in TIM-4 KO mice. The BMs of CD45.2 $2^{+}$TIM$4 \mathrm{KO}$ mice and $\mathrm{CD} 45.1^{+}$B6.SJL mice were mixed at a 1:1 ratio and transferred into lethally irradiated CD45.1 $1^{+} / \mathrm{CD} 45.2$ B6.SJL hosts. Eight weeks later, reconstituted animals were analyzed by flow cytometry. a. Flow cytometry analysis (left panel) and frequency (right panel) of thymus and spleen iNKT cells originated from the CD45.1 $1^{+}$B6.SJL and CD45.2 $2^{+}$TIM-4 KO BMs. b. Flow cytometry analysis of iNKT developmental stages gated on the B6.SJL- and TIM-4 KO-derived thymus iNKT cells (left panel). The percentage of each iNKT developmental subset (right panel). c. Flow cytometry analysis (left panel) and percentage (right panel) of NK1.1, CD69 and CD122 expressions in the B6.SJL- and TIM-4 KO-derived splenic iNKT cells. d. Flow cytometry analysis (left panel) and ratio (right panel) of IFN- $\gamma$-, IL-4-, IL-17- and CD69-positive splenic NKT cells from the B6.SJL and TIM-4 KO BMs after PMA and ionomycin treatment in vitro for 3 hours. e. Flow cytometry analysis (left panel) and frequency (right panel) of T-bet, GATA-3 and ROR $\gamma t$ expressions in the B6.SJL- and TIM-4 KO-derived splenic iNKT cells. Data represent 3 to 4 chimeric mice. 
deletion [36]. However, galectin-9 stimulation on Kupffer cells also increased their secretion of IL-15, which would enhance hepatic NKT cell proliferation [36]. Lately, Kadowaki et al [37] reported that galectin-9 upregulated the frequency of splenic NKT cells, particularly TIM-3expressing NK $1.1^{+} \mathrm{NKT}$ cells and further IL- $17^{+} \mathrm{NK} 1.1^{+}$ NKT cells. In contrast with TIM-1 and TIM-3, the role of TIM-4 in NKT cell biology remains largely unexplored.

Recently, Kim et al [31] discovered that unlike conventional T cells, both mouse hepatic iNKT cells and DN32.D3 NKT hybridoma cells constitutively expressed TIM-4. Notably, rTIM-4 alone, but not rTIM-1, could enhance the cytokine production of DN32.D3 cells, implying that TIM-4 might play a crucial role in iNKT cell activity [31]. Moreover, silencing of TIM-4 in DN32. D3 cells significantly hampering cytokine secretion induced by TIM-1 engagement along with TCR stimulus, indicating that TIM-4 is also critically involved in the activation of iNKT cells mediated by TIM-1 signaling [31]. Considering that TIM-1 and TIM-4 act as ligands mutually, these results suggested that TIM-4 might serve as an essential costimulatory molecule for iNKT cell activity. In our study, we utilized TIM-4-deficient mice to assess the role of TIM-4 in the biology of iNKT cells, and discovered that lack of TIM-4 does not affect iNKT cell differentiation, maturation or cytokine secretion in a cell-intrinsic manner. The discrepancy between previous data and our results are probably due to: (1) the in vitro supplement of rTIM-4 might produce a higher level of TIM-4 exceeding normal physiological range; (2) TIM-4 might be redundant for iNKT cell activity in the absence of TIM-1 engagement; (3) DN32.D3 cells are a V $\alpha 14^{+}$ CD1d-specific NKT hybridoma cell line, which probably differ from normal iNKT cells in some aspects; (4) it is possible that recombinant protein mediated ligation and RNA interference might produce unpredictable off-target effects, which could bring about confounding factors in interpreting the role of TIM-4 in iNKT cell biology. Nonetheless, we cannot rule out the possibility that TIM-4 might participate in the other unexamined properties of iNKT cells, which include their anergy induction [38], infrequent sublineage (NKT10 or follicular helper NKT cells) polarization $[39,40]$ and disease-associated immune functions [41-43]. Limitations of this study also involve the potential impaired phagocytosis of TIM-4-deficient APCs, which might compromise the CD1d-restricted presentation of $\alpha$-Galcer to iNKT cells and subsequently disguise their altered cytokine-secreting function [24, 44]. Future studies, especially with the utility of compartmentspecific TIM-4 ablated mice, would provide a better insight into these unanswered questions.

In conclusion, we demonstrate that TIM-4 is differentially expressed on iNKT cells according to their location and maturation status. Moreover, lack of TIM4 does not disturb iNKT cell development, maturation, functions and NKT1/NKT2/NKT17 polarization, indicating that TIM-4 is not a key gene in regulating iNKT cell biology.

\section{MATERIALS AND METHODS}

\section{Mice}

TIM-4 KO mice were described previously [24], and kindly provided by Dr. Vijay K. Kuchroo (Brigham and Women's Hospital, Harvard Medical School). C57BL/6 wild-type mice were purchased from the Jackson Laboratory. Experiments were conducted at 7 to 10 weeks of age, unless otherwise indicated. Mice were housed in a specific pathogen-free barrier unit. Handling of mice and experimental procedures were in accordance with requirements of the Institutional Animal Care and Use Committee.

\section{Genotyping}

TIM-4 KO mice were genotyped using the following PCR primer pairs: TIM-4 FW 5'-TAGCACAGGTTTTGCGTGAC-3', TIM-4 WT RV 5'-CTCTGGGACCACGAGAGGTA-3' and TIM-4 KO RV 5'-GCCAGAGGCCACTTGTGTAG-3'. The TIM-4 deletion allele produced a 250-bp PCR product, whereas the wild-type allele resulted in a 400 -bp product.

\section{Flow cytometry and antibodies}

Single-cell suspensions were incubated with antiFc $\gamma$ RII/III (clone 2.4G2) for 10 minutes at $4^{\circ} \mathrm{C}$, and subsequently stained for surface and intracellular markers with the conjugated monoclonal antibodies listed as below: Anti-B220 (RA3-6B2), anti-TCR- $\beta$ (H57-597), anti-CD44 (IM7), anti-NK1.1 (PK136), anti-CD69 (H1.2F3), anti-CD122 (5H4), anti-T-bet (ebio4B10), anti-GATA-3 (TWAJ), anti-ROR $\gamma \mathrm{t}$ (B2D), anti-CD45.1 (A20), anti-CD45.2 (104), anti-Ki67 (SolA15), anti-IFN- $\gamma$ (XMG1.2), anti-IL-4 (11B11), anti-IL-17 (ebio17B7) and Annexin $\mathrm{V}$ were purchased from BD Biosciences (San Jose, CA, USA) or eBioscience (San Diego, CA, USA). Lipid PBS-57 (an analogue of $\alpha$-GalCer)-loaded murine CD1d tetramers were provided by the National Institutes of Health Tetramer Facility (Atlanta, GA, USA). Data were analyzed using FlowJo software.

\section{In vivo $\alpha$-GalCer-induced activation assay}

Two micrograms of $\alpha$-GalCer in $100 \mu 1$ of PBS was injected into the tail vein. For intracellular cytokine staining, spleen cells were collected 2 hours after injection and cultured in T cell medium (RPMI 1640 with $10 \%$ 
FCS, HEPES, penicillin and streptomycin, pyruvate, nonessential amino acids, L-glutamine and 2-ME). Golgistop was added to a final concentration of $3 \mathrm{mM}$, and the cells were incubated for an additional hour. Cells were extracellularly stained with anti-TCR- $\beta$ antibody and CD1d tetramer. IFN- $\gamma$ and IL-4 expressions were detected by intracellular staining and flow cytometry.

\section{In vitro PMA and ionomycin activation assay}

Spleen and LN cells were cultured in T cell medium in the presence of PMA $(50 \mathrm{ng} / \mathrm{ml})$ and ionomycin $(1 \mathrm{mM})$ for 1 hour; Golgistop was added to a final concentration of $3 \mathrm{mM}$; and the cells were incubated for an additional 2 hours. IFN- $\gamma$, IL-4 and IL-17 expressions were detected by intracellular staining and flow cytometry.

\section{Mixed bone marrow transfer experiments}

To generate bone marrow (BM) chimeras, 6- to 8-wk-old B6.SJL recipient mice $\left(\mathrm{CD} 45.1^{+} / \mathrm{CD} 45.2\right)$ were lethally irradiated initially with $950 \mathrm{rad}$. Donor BMs were harvested from age- and sex-matched B6.SJL (CD45.1 $\left.1^{+}\right)$ and TIM-4 KO mice (CD45.2+) by flushing with a syringe containing sterile basal tissue culture medium. After erythrocyte lysis, mature T cells were depleted by biotinconjugated anti-mouse CD3 (BD Biosciences) monoclonal antibodies and anti-biotin magnetic beads (Miltenyi Biotec) from BMs from each donor, using an AutoMACS sorter (Miltenyi Biotec). Over 90\% of mature T cell depletion was confirmed by flow cytometry. CD45.1 ${ }^{+}$ B6.SJL and CD45.2+ TIM-4 KO mice BMs were mixed at a 1:1 ratio, and 10 million cells per mouse (in a volume of $100 \mu \mathrm{l}$ ) were then injected into the irradiated recipients via tail vein. The chimeras were analyzed 8 weeks after reconstitution.

\section{Statistical analysis}

Statistical analysis was performed with Prism 5.0 (GraphPad Software). The two-tailed Student t test was used. Differences were considered statistically significant when values of $p<0.05$.

\section{ACKNOWLEDGMENTS}

We thank Dr. Vijay K. Kuchroo for TIM-4 KO mice, and all members of our laboratory for their advice and encouragement. This work was supported in part by a grant from National Institutes of Health Grant R561AI119041 and 1R01AI119041, and the Henry Ford Health System Research Grant for the Immunology Program (T71016 and T71016).

\section{CONFLICTS OF INTEREST}

The authors state no conflict of interest.

\section{REFERENCES}

1. Taniguchi M, Koseki H, Tokuhisa T, Masuda K, Sato H, Kondo E, Kawano T, Cui J, Perkes A and Koyasu S. Essential requirement of an invariant $\mathrm{V}$ alpha $14 \mathrm{~T}$ cell antigen receptor expression in the development of natural killer T cells. Proceedings of the National Acdemy of Sciences. 1996; 93:11025-11028.

2. Godfrey DI, MacDonald HR, Kronenberg M, Smyth MJ and Van Kaer L. NKT cells: what's in a name? Nature reviews Immunology. 2004; 4:231-237.

3. Bendelac A, Savage PB and Teyton L. The biology of NKT cells. Annu Rev Immunol. 2007; 25:297-336.

4. Subleski JJ, Jiang Q, Weiss JM and Wiltrout RH. The split personality of NKT cells in malignancy, autoimmune and allergic disorders. Immunotherapy. 2011; 3:1167-1184.

5. Berzofsky JA and Terabe M. NKT cells in tumor immunity: opposing subsets define a new immunoregulatory axis. Journal of immunology (Baltimore, Md : 1950). 2008; 180:3627-3635.

6. Gapin L, Matsuda JL, Surh CD and Kronenberg M. NKT cells derive from double-positive thymocytes that are positively selected by CD1d. Nature immunology. 2001; 2:971-978.

7. Benlagha K, Kyin T, Beavis A, Teyton L and Bendelac A. A thymic precursor to the NK T cell lineage. Science. 2002; 296:553-555.

8. Pellicci DG, Hammond KJ, Uldrich AP, Baxter AG, Smyth MJ and Godfrey DI. A natural killer T (NKT) cell developmental pathway involving a thymus-dependent NK1. 1 CD4+ CD1d-dependent precursor stage. The Journal of experimental medicine. 2002; 195:835-844.

9. Godfrey DI and Berzins SP. Control points in NKT-cell development. Nature Reviews Immunology. 2007; 7:505518.

10. Berzins SP, McNab FW, Jones CM, Smyth MJ and Godfrey DI. Long-term retention of mature NK1. 1+ NKT cells in the thymus. The Journal of Immunology. 2006; 176:40594065.

11. Lee YJ, Holzapfel KL, Zhu J, Jameson SC and Hogquist KA. Steady-state production of IL-4 modulates immunity in mouse strains and is determined by lineage diversity of iNKT cells. Nature immunology. 2013; 14:1146-1154.

12. Constantinides $\mathrm{MG}$ and Bendelac A. Transcriptional regulation of the NKT cell lineage. Current opinion in immunology. 2013; 25:161-167.

13. McIntire JJ, Umetsu SE, Akbari O, Potter M, Kuchroo VK, Barsh GS, Freeman GJ, Umetsu DT and DeKruyff RH. Identification of Tapr (an airway hyperreactivity regulatory 
locus) and the linked Tim gene family. Nature immunology. 2001; 2:1109-1116.

14. Kuchroo VK, Umetsu DT, DeKruyff RH and Freeman GJ. The TIM gene family: emerging roles in immunity and disease. Nature Reviews Immunology. 2003; 3:454-462.

15. Santiago C, Ballesteros A, Tami C, Martínez-Muñoz L, Kaplan GG and Casasnovas JM. Structures of T cell immunoglobulin mucin receptors 1 and 2 reveal mechanisms for regulation of immune responses by the TIM receptor family. Immunity. 2007; 26:299-310.

16. Li Z, Ju Z and Frieri M. (2013). The T-cell immunoglobulin and mucin domain (Tim) gene family in asthma, allergy, and autoimmunity. Allergy and Asthma Proceedings: OceanSide Publications, Inc), pp. e21-e26.

17. Rennert PD. Novel roles for TIM-1 in immunity and infection. Immunology letters. 2011; 141:28-35.

18. Baghdadi $M$ and Jinushi $M$. The impact of the TIM gene family on tumor immunity and immunosuppression. Cellular \& molecular immunology. 2014; 11:41-48.

19. Xiao S, Najafian N, Reddy J, Albin M, Zhu C, Jensen E, Imitola J, Korn T, Anderson AC and Zhang Z. Differential engagement of Tim-1 during activation can positively or negatively costimulate $\mathrm{T}$ cell expansion and effector function. The Journal of experimental medicine. 2007; 204:1691-1702.

20. Chakravarti S, Sabatos CA, Xiao S, Illes Z, Cha EK, Sobel RA, Zheng XX, Strom TB and Kuchroo VK. Tim-2 regulates $T$ helper type 2 responses and autoimmunity. The Journal of experimental medicine. 2005; 202:437-444.

21. Zhu C, Anderson AC, Schubart A, Xiong H, Imitola J, Khoury SJ, Zheng XX, Strom TB and Kuchroo VK. The Tim-3 ligand galectin-9 negatively regulates T helper type 1 immunity. Nature immunology. 2005; 6:1245-1252.

22. Shakhov AN, Rybtsov S, Tumanov AV, Shulenin S, Dean M, Kuprash DV and Nedospasov SA. SMUCKLER/TIM4 is a distinct member of TIM family expressed by stromal cells of secondary lymphoid tissues and associated with lymphotoxin signaling. European journal of immunology. 2004; 34:494-503.

23. Meyers JH, Chakravarti S, Schlesinger D, Illes Z, Waldner H, Umetsu SE, Kenny J, Zheng XX, Umetsu DT and DeKruyff RH. TIM-4 is the ligand for TIM-1, and the TIM1-TIM-4 interaction regulates $\mathrm{T}$ cell proliferation. Nature immunology. 2005; 6:455-464.

24. Rodriguez-Manzanet R, Sanjuan MA, Wu HY, Quintana FJ, Xiao S, Anderson AC, Weiner HL, Green DR and Kuchroo VK. T and B cell hyperactivity and autoimmunity associated with niche-specific defects in apoptotic body clearance in TIM-4-deficient mice. Proceedings of the National Academy of Sciences. 2010; 107:8706-8711.

25. Zhang X, Liu Q, Wang J, Li G, Weiland M, Yu FS, Mi QS, Gu J and Zhou L. TIM-4 is differentially expressed in the distinct subsets of dendritic cells in skin and skin-draining lymph nodes and controls skin langerhans cell homeostasis.
Oncotarget. 2016; 7: 37498-37512. doi:10.18632/ oncotarget.9546.

26. Park D, Hochreiter-Hufford A and Ravichandran KS. The phosphatidylserine receptor TIM-4 does not mediate direct signaling. Current Biology. 2009; 19:346-351.

27. Mizui M, Shikina T, Arase H, Suzuki K, Yasui T, Rennert PD, Kumanogoh A and Kikutani H. Bimodal regulation of $\mathrm{T}$ cell-mediated immune responses by TIM-4. International immunology. 2008; 20:695-708.

28. Yang PC, Xing Z, Berin CM, Soderholm JD, Feng BS, Wu L and Yeh C. TIM-4 Expressed by Mucosal Dendritic Cells Plays a Critical Role in Food Antigen-Specific Th2 Differentiation and Intestinal Allergy. Gastroenterology. 2007; 133:1522-1533.

29. Cao W, Ryan M, Buckley D, O'Connor R and Clarkson MR. Tim - 4 inhibition of T-cell activation and T helper type 17 differentiation requires both the immunoglobulin $\mathrm{V}$ and mucin domains and occurs via the mitogen-activated protein kinase pathway. Immunology. 2011; 133:179-189.

30. Yeung MY, McGrath MM, Nakayama M, Shimizu T, Boenisch O, Magee CN, Abdoli R, Akiba H, Ueno T, Turka LA and Najafian N. Interruption of dendritic cell-mediated TIM-4 signaling induces regulatory $\mathrm{T}$ cells and promotes skin allograft survival. Journal of immunology (Baltimore, Md : 1950). 2013; 191:4447-4455.

31. Kim HS, Kim HS, Lee CW and Chung DH. T cell Ig domain and mucin domain 1 engagement on invariant NKT cells in the presence of TCR stimulation enhances IL-4 production but inhibits IFN- production. The Journal of Immunology. 2010; 184:4095-4106.

32. Liu T, He S-H, Zheng P-Y, Zhang T-Y, Wang B-Q and Yang P-C. Staphylococcal enterotoxin B increases TIM4 expression in human dendritic cells that drives naive CD4 T cells to differentiate into Th2 cells. Molecular immunology. 2007; 44:3580-3587.

33. Feng B-S, Chen X, He S-H, Zheng P-Y, Foster J, Xing $\mathrm{Z}$, Bienenstock $\mathrm{J}$ and Yang P-C. Disruption of T-cell immunoglobulin and mucin domain molecule (TIM)-1/ TIM4 interaction as a therapeutic strategy in a dendritic cell-induced peanut allergy model. Journal of Allergy and Clinical Immunology. 2008; 122:55-61. e57.

34. Kim HY, Eyheramonho MB, Pichavant M, Cambaceres CG, Matangkasombut P, Cervio G, Kuperman S, Moreiro R, Konduru K and Manangeeswaran M. A polymorphism in TIM1 is associated with susceptibility to severe hepatitis A virus infection in humans. The Journal of clinical investigation. 2011; 121:1111.

35. Lee H-H, Meyer EH, Goya S, Pichavant M, Kim HY, Bu X, Umetsu SE, Jones JC, Savage PB and Iwakura Y. Apoptotic Cells Activate NKT Cells through T Cell Ig-Like MucinLike-1 Resulting in Airway Hyperreactivity. The Journal of Immunology. 2010; 185:5225-5235.

36. Tang Z-H, Liang S, Potter J, Jiang X, Mao H-Q and Li Z. Tim-3/galectin-9 regulate the homeostasis of hepatic NKT 
cells in a murine model of nonalcoholic fatty liver disease. The Journal of Immunology. 2013; 190:1788-1796.

37. Kadowaki T, Morishita A, Niki T, Hara J, Sato M, Tani J, Miyoshi H, Yoneyama H, Masaki $\mathrm{T}$ and Hattori T. Galectin-9 prolongs the survival of septic mice by expanding tim-3-expressing natural killer $\mathrm{T}$ cells and PDCA-1+ CD11c+ macrophages. Critical Care. 2013; 17:R284.

38. Sullivan BA and Kronenberg M. Activation or anergy: NKT cells are stunned by alpha-galactosylceramide. J Clin Invest. 2005; 115:2328-2329.

39. Wingender G, Sag D and Kronenberg M. NKT10 cells: a novel iNKT cell subset. Oncotarget. 2015; 6:26552-26553. doi:10.18632/oncotarget.5270.

40. Chang PP, Barral P, Fitch J, Pratama A, Ma CS, Kallies A, Hogan JJ, Cerundolo V, Tangye SG, Bittman R, Nutt SL, Brink R, Godfrey DI, Batista FD and Vinuesa CG. Identification of Bcl-6-dependent follicular helper NKT cells that provide cognate help for B cell responses. Nat Immunol. 2012; 13:35-43.
41. van der Vliet HJ, Molling JW, von Blomberg BM, Nishi N, Kolgen W, van den Eertwegh AJ, Pinedo HM, Giaccone $\mathrm{G}$ and Scheper RJ. The immunoregulatory role of CD1d-restricted natural killer T cells in disease. Clinical immunology (Orlando, Fla). 2004; 112:8-23.

42. Wu L and Van Kaer L. Natural killer T cells in health and disease. Frontiers in bioscience (Scholar edition). 2011; 3:236-251.

43. Berzins SP, Smyth MJ and Baxter AG. Presumed guilty: natural killer $\mathrm{T}$ cell defects and human disease. Nature reviews Immunology. 2011; 11:131-142.

44. Barral P, Polzella P, Bruckbauer A, van Rooijen N, Besra GS, Cerundolo V and Batista FD. CD169(+) macrophages present lipid antigens to mediate early activation of iNKT cells in lymph nodes. Nat Immunol. 2010; 11:303-312. 